\title{
The prevalence of asthma in patients with obstructive sleep apnoea
}

\section{Mohammed Alharbia, Abdulelah Almutairia, Dhawi Alotaibia , Azam Alotaibia , Shaffi Shaikh ${ }^{\mathrm{b}}$, *Ahmed S BaHammama}

a Sleep Disorders Center, King Saud University, Riyadh, Saudi Arabia

${ }^{\mathrm{b}}$ Family and Community Medicine, King Saud University, Riyadh, Saudi Arabia

Originally submitted 14th July 2008; resubmitted 22nd October 2008; revised version received 28th November 2008; accepted 31st January 2009; online 30th April 2009

\begin{abstract}
Background: Most of the studies that have explored the relationship between obstructive sleep apnoea (OSA) and asthma have focused on the prevalence of snoring and OSA symptoms in patients with asthma.

Objectives: This study was conducted to measure the reverse relationship - the prevalence of asthma in patients with diagnosed OSA. Methods: We assessed the prevalence of asthma in all patients diagnosed polysomnographically to have OSA during the study period. A logistic regression model was developed to assess the predictors for asthma in patients with OSA.

Results: Six-hundred-and-six patients with OSA with a mean age of $40 \pm 14.5 \mathrm{yr}(66.7 \%$ males) were included. Asthma was present in 213 OSA patients - a prevalence of $35.1 \%$. Body mass index $\left(>35 \mathrm{~kg} / \mathrm{m}^{2}\right)$ was the only predictor of asthma.

Conclusions: Physicians should keep in mind the link between OSA and asthma. When one of these disorders is diagnosed, clinicians should consider the possible presence of the other.

(C) 2009 General Practice Airways Group. All rights reserved

AS BaHammam et al. Prim Care Resp J 2009; 18(4): 328-330

doi:10.4104/pcrj.2009.00020
\end{abstract}

Keywords asthma, diagnosis, obstructive sleep apnoea, prevalence

\section{Introduction}

Asthma is a lung disease characterised by airway inflammation resulting in reversible airway obstruction. ${ }^{1}$ Obstructive sleep apnoea (OSA) is a common sleep-related breathing disorder characterised by temporary cessation of airflow during sleep for 10 seconds or more despite continuing ventilatory effort. ${ }^{2}$ About $4 \%$ and $2 \%$ of middleaged men and women, respectively, suffer from symptomatic OSA. These percentages are higher (24\% for men and $9 \%$ for women) when an apnoea/hypopnea index (AHI) of 5 or more is present regardless of co-existent daytime somnolence. ${ }^{2} \mathrm{~A}$ greater proportion of asthma patients tend to die at night than in the general population. ${ }^{3}$ In addition, Gami et al. found that sudden death of OSA patients occurs more commonly between midnight and 06.00 and correlates with a worsening $\mathrm{AHI}{ }^{4}$

OSA and asthma are common, share similar nocturnal symptoms, and involve airway obstruction (albeit at different levels in each condition ${ }^{5}$ ) as the cornerstone of their pathophysiology. Most of the studies that have explored the relationship between OSA and asthma have focused on the prevalence of snoring and OSA symptoms in patients with asthma. ${ }^{6-9}$ Both obesity and OSA act to aggravate existing asthma making it more difficult to control symptoms. ${ }^{10}$ However, to our knowledge, no study has directly addressed the reverse relationship - i.e. the prevalence of asthma in patients with a confirmed diagnosis of OSA. Therefore, we conducted this study to measure the prevalence of asthma in patients diagnosed to have OSA in the sleep disorders center (SDC) and to define the characteristics of patients with OSA who do have asthma.

\section{Methods}

All patients who were referred to the SDC in our institute

\footnotetext{
* Corresponding author: Professor Ahmed S BaHammam, Sleep Disorders Center, Department of Medicine, King Saud University, P.O. Box 225503 Riyadh 11324, Saudi Arabia. Tel: +00966 14671521 Fax: +009661467 2558 E-mail: ashammam2@gmail.com
} 
from the outpatient clinics between March 2003 and October 2007 and who were diagnosed to have OSA - based on a type I attended overnight sleep study (polysomnography) and according to the International Criteria of Sleep Disorders (ICSD) $)^{11}$ - were included. The definition of asthma was based on a respiratory questionnaire. ${ }^{12-14}$ The three questions selected from this questionnaire were as follows: (1) Have you ever had asthma? (2) Do you still have it? (3) Was it confirmed by a doctor? Definite asthma was defined as positive responses to these three questions. ${ }^{6}$ Sleep studies of patients who had audible wheezing on auscultation or who reported uncontrolled symptoms were postponed until symptoms were controlled. Patients who were labelled by their treating doctors to have COPD were excluded.

The following demographic and polysomnographic parameters were identified: age; gender; current history of smoking; body mass index (BMI); $\mathrm{AHI}$ (the number of apnoea/hypopnoea episodes per hour of sleep); arousal index (i.e., arousals/hour); desaturation index (the number of desaturation events per hour of sleep); and the lowest $\mathrm{O}_{2}$ saturation during sleep. Daytime sleepiness was assessed using the Epworth Sleepiness Scale (ESS) ${ }^{15}$ which is a validated, specialised sleep questionnaire containing eight items that assess the likelihood of dozing in a variety of situations.

Data were analysed using SPSS PC version 11.0 statistical software. Descriptive statistics (mean, standard deviation and proportions) were used to describe the study variables. Student's t-test for two independent samples was used to compare the mean values of continuous study variables. A logistic regression model was used to identify the independent predictors of asthma in OSA patients. Crude and adjusted odds ratios with its $95 \%$ confidence intervals were calculated. A pvalue of $\leq 0.05$ was considered as statistically significant.

The study was approved by the ethics committee in our institute and informed consent was obtained from all patients.

\section{Results}

Six-hundred-and-six patients with OSA with a mean age of $40 \pm 14.5 \mathrm{yr}(66.7 \%$ males) were included. Asthma was present in 213 , a prevalence rate of $35.1 \%$. Forty-seven percent of OSA patients with asthma were females and $53 \%$ were males.

Table 1 presents a comparison between OSA patients with and without asthma. BMI, AHI and lowest oxygen saturation were significantly higher in OSA patients with asthma compared to those without asthma. There was no difference in smoking history between OSA patients with and without asthma; $10.5 \%$ vs. $15.6 \%(p=0.1)$. Additionally, no significant differences were found in the mean values of arousal index and ESS score. Body mass index $\left(>35 \mathrm{~kg} / \mathrm{m}^{2}\right)$ was the only predictor of asthma in the multivariate logistic regression model (crude odds ratio 2.05; 95\% confidence interval (Cl)
Table 1. Demographic and polysomnographic features of OSA patients with and without asthma.

\begin{tabular}{lccc} 
& $\begin{array}{c}\text { OSA patients } \\
\text { with asthma }\end{array}$ & $\begin{array}{c}\text { OSA patients } \\
\text { without asthma }\end{array}$ & p-value \\
\hline Age & $46.9 \pm 14.2$ & $45.7 \pm 15.3$ & 0.3 \\
BMI & $38.3 \pm 9.4$ & $35.4 \pm 9.9$ & 0.001 \\
ESS & $9.8 \pm 6.2$ & $9.4 \pm 5.9$ & 0.4 \\
AHI & $53.9 \pm 37.8$ & $47.8 \pm 36.8$ & 0.05 \\
Desaturation index & $32.4 \pm 29.4$ & $31.4 \pm 30.2$ & 0.7 \\
Lowest O 2 saturation & $79.6 \pm 13.4$ & $81.7 \pm 11.6$ & 0.04 \\
Arousal index & $55.7 \pm 33.1$ & $52.7 \pm 33.9$ & 0.3 \\
\hline BMI, body mass index; ESS, Epworth Sleepiness Scale; AHI, apnoea & \\
hypopnoea index; OSA, obstructive sleep apnoea. &
\end{tabular}

1.4, 2.9: adjusted odds ratio $2.1 ; 95 \% \mathrm{Cl}: 1.7,2.4)$. The other variables were not predictors of asthma in OSA patients neither in univariate nor multivariate analyses.

\section{Discussion}

This study demonstrates a high prevalence of asthma (35.1\%) in patients with OSA as compared to the prevalence of asthma in the general population. ${ }^{16}$ OSA patients with asthma had a higher $\mathrm{BMI}$ and $\mathrm{AHI}$ compared to OSA patients without asthma. Body mass index $\geq 35 \mathrm{~kg} / \mathrm{m}^{2}$ was a significant predictor of asthma in OSA patients. Both OSA and asthma have been linked to obesity - obesity is a well-known risk factor for OSA and the size of the upper airways has been shown to correlate with OSA. ${ }^{17}$ On the other hand, there have been numerous reports in the literature suggesting an association between wheezing, asthma, and obesity. ${ }^{17}$

The arousal index in the two groups was not significantly different due to the fact that we only included stable asthmatics on treatment. Despite the fact that physicians have long noticed an association between the symptoms of OSA and asthma, ${ }^{18}$ previous studies have only explored the prevalence of OSA symptoms and snoring in asthmatic patients and no study has explored the relationship in reverse - the prevalence of asthma in polysomnographicallydiagnosed OSA patients. A number of studies have reported a higher prevalence of snoring among asthmatic patients compared with non-asthmatic patients. ${ }^{6,7,19}$ A $20.5 \%$ prevalence of habitual snoring ( $\geq 3$ nights per week) was reported in a large population-based cohort of young atopic women. ${ }^{19}$ Yigla and colleagues performed an overnight sleep study for 22 consecutive patients with severe unstable asthma who required intermittent oral corticosteroid therapy and demonstrated OSA in 21 (95.5\%) of these patients, despite the observation that this group had a normal mean BMI. ${ }^{10}$

In the present study, OSA was more severe in patients who 
have concurrent asthma. Although a cause and effect relationship has not been established, several theories have been proposed for the relationship between OSA and asthma. The recurrent upper airway obstruction might cause reflex bronchoconstriction by stimulating neural receptors in the pharyngeal region or by generating negative intrathoracic pressure. ${ }^{9,20}$ Another plausible explanation relates to gastrooesophageal reflux (GOR); it is known that the large intrapleural pressure swings during apnoeic episodes facilitates $\mathrm{GOR}^{21}$ and GOR is a potential trigger of asthma that may occur even without oesophageal symptoms. ${ }^{22}$ Recently, studies have shown that OSA is associated with systemic inflammation. ${ }^{23}$ Theoretically, OSA may contribute to the development of lower airway obstruction through its effect on airway inflammation. Good support for a cause and effect relationship between OSA and asthma comes from studies that showed improvement in asthma after treating OSA. Chan et al. demonstrated in nine patients with asthma and concurrent OSA that the initiation of continuous positive airway pressure (CPAP) therapy resulted in marked improvement in their asthma, with decreased symptoms, improved peak expiratory flow rate, reduced need for bronchodilator therapy, and resolution of their pattern of nocturnal worsening. ${ }^{24} \mathrm{~A}$ recent prospective study of 20 patients with severe OSA and concurrent asthma demonstrated that CPAP therapy results in significant improvement in asthma quality of life..$^{25}$

A limitation of this study is the fact that we relied on the referring physicians' diagnosis and patients' response to a standardised questionnaire to define asthma, and did not perform spirometry to assess the bronchodilator response in the SDC. Nevertheless, most of the studied asthmatics were controlled on inhaled steroids at the time of referral to the SDC, which makes the assessment of bronchodilator response less beneficial.

The present study demonstrates that asthma is prevalent in patients with OSA. Physicians in general and primary care physicians in particular should keep in mind the link between the two disorders. When one of these disorders is diagnosed, clinicians should consider the possible presence of the other.

\section{Conflict of interest declaration}

The authors declare that they have no conflicts of interest in relation to this article.

\section{References}

1. Goldstein RA, Paul WE, Metcalfe DD, Busse WW, Reece ER. NIH conference. Asthma. Ann Intern Med 1994;121(9):698-708.

2. Young T, Palta M, Dempsey J, Skatrud J, Weber S, Badr S. The occurrence of sleep-disordered breathing among middle-aged adults. N Engl I Med 1993; 328(17):1230-5. http://dx.doi.org/10.1056/NEJM199304293281704

3. Douglas NJ. Asthma at night. Clin Chest Med 1985;6(4):663-74.

4. Gami AS, Howard DE, Olson EJ, Somers VK. Day-night pattern of sudden death in obstructive sleep apnea. N Engl J Med 2005;352(12):1206-14. http://dx.doi.org/10.1056/NEJMoa041832

5. Kasasbeh A, Kasasbeh E, Krishnaswamy G. Potential mechanisms connecting asthma, esophageal reflux, and obesity/sleep apnea complex--a hypothetical review. Sleep Med Rev 2007;11(1):47-58. http://dx.doi.org/ 10.1016/j.smrv.2006.05.001

6. Ekici A, Ekici M, Kurtipek E, et al. Association of asthma-related symptoms with snoring and apnea and effect on health-related quality of life. Chest 2005;128(5):3358-63. http://dx.doi.org/10.1378/chest.128.5.3358

7. Fitzpatrick MF, Martin K, Fossey E, Shapiro CM, Elton RA, Douglas NJ. Snoring, asthma and sleep disturbance in Britain: a community-based survey. Eur Respir J 1993;6(4):531-5.

8. Larsson LG, Lindberg A, Franklin KA, Lundback B. Symptoms related to obstructive sleep apnoea are common in subjects with asthma, chronic bronchitis and rhinitis in a general population. Respir Med 2001;95(5):423-9. http://dx.doi.org/10.1053/rmed.2001.1054

9. Shigemitsu H, Afshar K. Nocturnal asthma. Curr Opin Pulm Med 2007; 13(1):49-55. http://dx.doi.org/10.1097/MCP.0b013e328010a890

10. Yigla $\mathrm{M}$, Tov $\mathrm{N}$, Solomonov $\mathrm{A}$, Rubin $\mathrm{AH}$, Harlev D. Difficult-to-control asthma and obstructive sleep apnea) J Asthma 2003;40(8):865-71. http://dx.doi.org/ 10.1081/JAS-120023577

11. American Academy of Sleep Medicine. International classification of sleep disorders (ICSD), 2nd ed. :Diagnostic and coding manual. Westchester(IL): American Academy of Sleep Medicine, 2005.

12. Enright PL, McClelland RL, Newman AB, Gottlieb DJ, Lebowitz MD. Underdiagnosis and undertreatment of asthma in the elderly. Cardiovascular Health Study Research Group. Chest 1999;116(3):603-13

13. Ferris BG. Epidemiology Standardization Project (American Thoracic Society). Am Rey Respir Dis 1978;118(6 Pt 2):1-120.

14. BMJ Research Council Committee on the Aetiology of Chronic Bronchitis. Standardized questionnaire on respiratory symptoms. BMJ 1960;2:165.

15. Johns MW. A new method for measuring daytime sleepiness: the Epworth sleepiness scale. Sleep 1991;14(6):540-5.

16. Al Frayh AR, Shakoor Z, Gad El Rab MO, Hasnain SM. Increased prevalence of asthma in Saudi Arabia. Ann Allergy Asthma Immunol 2001;86(3):292-6.

17. Deane S, Thomson A. Obesity and the pulmonologist. Arch Dis Child 2006;91(2):188-91. http://dx.doi.org/10.1136/adc.2005.072223

18. Guilleminault C, Quera-Salva MA, Powell N, et al. Nocturnal asthma: snoring, small pharynx and nasal CPAP. Eur Respir J 1988;1(10):902-07.

19. Kalra $M$, Biagini J, Bernstein $D$, et al. Effect of asthma on the risk of obstructive sleep apnea syndrome in atopic women. Ann Allergy Asthma Immunol 2006;97(2):231-5

20. Bohadana AB, Hannhart B, Teculescu DB. Nocturnal worsening of asthma and sleep-disordered breathing. J Asthma 2002;39(2):85-100.

21. Ing AJ, Ngu MC, Breslin AB. Obstructive sleep apnea and gastroesophageal reflux. Am J Med 2000;108 Suppl 4a:120S-5S. http://dx.doi.org/10.1016/ S0002-9343(99)00350-2

22. Harding SM, Guzzo MR, Richter JE. The prevalence of gastroesophageal reflux in asthma patients without reflux symptoms. Am J Respir Crit Care Med 2000;162(1):34-9.

23. Minoguchi K, Yokoe T, Tazaki T, et al. Increased carotid intima-media thickness and serum inflammatory markers in obstructive sleep apnea. Am J Respir Crit Care Med 2005;172(5):625-30. http://dx.doi.org/10.1164/rccm.200412$16520 \mathrm{C}$

24. Chan CS, Woolcock AJ, Sullivan CE. Nocturnal asthma: role of snoring and obstructive sleep apnea. Am Rev Respir Dis 1988;137(6):1502-04.

25. Lafond C, Series F, Lemiere C. Impact of CPAP on asthmatic patients with obstructive sleep apnoea. Eur Respir J 2007;29(2):307-11. http://dx.doi.org/ 10.1183/09031936.00059706 